\title{
El Libro de Artista de ayer a hoy: seis ancestros del Libro de Artista contemporáneo. Primeras aproxima- ciones y precedentes inmediatos
}

\section{The Artist's Book from yesterday to today: six ancestors of the contemporary Artist's Book. Firsts approaches and imme- diate precedents}

\author{
Bibiana CRespo-Martín \\ Profesora del Departamento de Dibujo de la Facultad de Bellas Artes de la Universidad de \\ Barcelona. \\ bbcrespo@ub.edu
}

Recibido: 04 de febrero de 2013

Aprobado: 15 de abril de 2013

\begin{abstract}
Resumen
Este artículo presenta las primeras aproximaciones y los precedentes inmediatos del Libro de Artista y expone los orígenes del proceso de transformación que éste experimentará a lo largo de los siglos XX y XXI con la finalidad de significar su desarrollo contemporáneo. Analizaremos la decisiva influencia en el desarrollo del Libro de Artista que han supuesto las series de grabados Carceri (c. 1745) de Giovanni Battista Piranesi y Caprichos (1799) de Francisco de Goya en cuanto a su concepción como obra única, el novedoso y experimental uso del aguafuerte de William Blake fusionando la labor de poeta y artista en su libro Songs of Innocence and of Experience (1794), el ideario de William Morris reflejado en su conferencia "The Ideal Book" (1893), el enigmático poema Un Coup de Dés (1895) de Stéphane Mallarmé abogando por la plasticidad y sonoridad tipográfica y la capital importancia de Ambroise Vollard como editor y concibiendo el libro como el resultado interdisciplinar de la colaboración entre el poeta, el artista y el propio editor.
\end{abstract}

Palabras clave: Libro de Artista, Bibliofilia, Grabado y edición, Libro Ilustrado, Livre de Peintre.

Crespo-Martín, B. (2014): El Libro de Artista de ayer a hoy: seis ancestros del Libro de Artista contemporáneo. Primeras aproximaciones y precedentes inmediatos. Arte, Individuo y Sociedad, 26 (2) 215-232.

\begin{abstract}
This article shows the firsts approaches and immediate precedents of Artist's Book and exposes the origins of the transformation process that it will expreriment during the Twentieth and Twentifirst Century in order to mean its contemporary development. We will analyze the decisive influence in the development of the Artist's Book that have meant the etching series of Giovanni Battista Piranesi's Carceri (c. 1745) and Francisco de Goya's Caprichos (1799) regarding their conception as a single
\end{abstract}


work, William Blake's novel and experimental use of etching joining poet and artist's task in his book Songs of Innocence and of Experience (1794), William Morris's ideology reflected in his lecture "The Ideal Book" (1893), the enigmatic poem Un Coup de Dés (1895) from Stéphane Mallarmé standing for a typographical plasticity and sound and the seminal importance of Ambroise Vollard as an editor that conceived the book as the consequence of the interdisciplinary collaboration between poet, artist and publisher.

Key words: Artist Book, Bibliophilia, Printmaking and edition, Illustrated Book, Livre de Peintre.

Crespo-Martín, B (2014). The Artist's Book from yesterday to today: six ancestors of the contemporary Artist's Book. Firsts approaches and immediate precedents. Arte, Individuo y Sociedad, 26(2) 215-232 .

Sumario: 1. Introducción, 2. Giovanni Battista Piranesi - Carceri, 3. Francico de Goya - Caprichos, 4. William Blake - Songs of Innocence and of Experience, 5. William Morris - "The Ideal Book", 6. Stéphane Mallarmé - Un Coup de Dés, 7. Ambroise Vollard - Pierre Bonnard - Parallèlement, 8. Conclusiones. Referencias

\section{Introducción}

El Libro de Artista (Phillpot, 1998) como objeto estético cuenta ya, en pleno siglo XXI, con una ilustre tradición. Durante el pasado siglo XX éste ha sido uno de los modos de creación dominantes de todos los movimientos artísticos cuya producción a menudo se concretizó en forma de libro, transformándolo en un objeto de expresión altamente personal. Todos los artistas contemporáneos han usado el libro para revelar sus ideologías estéticas adaptando todos los formatos, materiales y técnicas concebibles.

Pero el lógico y coherente proceso de transformación que el Libro de Artista ha ido experimentando debe su proceder a la imprescindible consideración de aquellos precedentes inmediatos del mismo que proporcionaron las claves idóneas para que durante el siglo XX y en nuestro siglo XXI, el libro, como soporte artístico autónomo, llegara a su mayoría de edad. Y, en este sentido, ciertos nombres propios han contribuido con su obra a la evolución y modernidad del Libro de Artista. Por ser obras muy extensas, de su conjunto, hemos seleccionado sólo una pieza, aquella que por sus particularidades ha aportado alguno de los rasgos que han sido decisivos en la posterior configuración del Libro de Artista como lo entendemos hoy.

\section{Giovanni Battista Piranesi - Carceri}

Giovanni Battista Piranesi (1720-1778) ¿grabador, arquitecto, arqueólogo? Una figura difícil de clasificar a pesar de que el artista siempre se consideró architetto veneziano. Según Enrique Lafuente Ferrari (1936: 22) "Si quisiéramos definir en una fórmula la esencia compleja del arte de Piranesi, podríamos decir que es la obra de un arquitecto con dotes de pintor que concentra su vocación en el grabado".

Posiblemente, de entre el conjunto de su obra, la serie de las Carceri son los grabados de Piranesi que más estudios han suscitado en toda la historia del grabado. 
En 1986, el catálogo de A. Robison (1986) estableció definitivamente los dibujos preparatorios, las estampas en sus diversos estados y las diferentes ediciones de la misteriosa serie. Y John Wilton-Ely en su estudio The Mind and Art of Giovanni Battista Piranesi (1988: 81) señala que:

La primera vez que aparecieron a mitad de 1740, las catorce estampas de Invenzioni Capric di Carceri representó una intensa obra privada, muy lejos de su tiempo en forma y contenido [...] esta obra surgió de lo que fue un breve periodo de crisis creativa, proporcionando una salida a una imaginación arquitectónica frustrada.

La primera edición de las Carceri, de la que se hicieron tres tirajes a cargo del editor Bouchard, suele datarse entre los años 1745 y 1750 . Constaba de catorce estampas, apareciendo en el frontispicio de la portada la siguiente inscripción: "INVENZIONI CAPRIC(ciose) DI CARCERI ACQUAFORTE IN LUCE DA GIOVANI BUZARD IN ROMA MERCANTE AL CORSO"-el nombre del editor apareció corregido en el segundo tiraje. Como indica su frontispicio, las Carceri eran esencialmente una serie de caprici. La palabra caprici ya había sido utilizada por otros grabadores para designar estampas o series de ellas que no pretendían reproducir hechos o sucesos reales, sino imaginaciones o variaciones sobre la realidad. En este sentido, las Carceri de Piranesi exponen una secuencia de invenciones y variaciones fantasiosas sobre un determinado tema -las cárceles.

La segunda edición (1761-1778) constaba de dieciséis -añadió los números II y V. Se realizaron cuatro tirajes y fueron publicados por el propio Piranesi. Además, sustituyó el frontispicio de la portada por el siguiente: “CARCERI D'INVENZIONE DI G. BATTISTA PIRANESI ARCHIT(etto) VENE(ziano)" (fig. 1), figurando en la cárcel II la dirección del artista: "en la calle Felice, al lado de Trinità de 'Monti". Esta serie definitiva es la que en la actualidad conocemos como Carceri d'Invenzione.

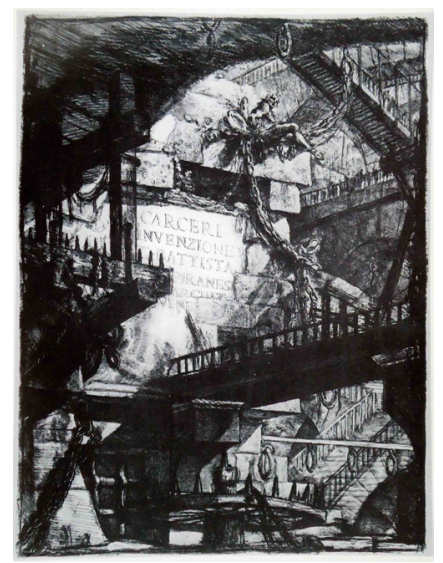

Figura 1. Giovanni Battista Piranesi, Invenzioni capric. di Carceri all'acquaforte datte in luce Giovani Buzard...hacia 1745. 2 ${ }^{\mathrm{a}}$ edición: Carceri d'invenzione di G. Battista Piranesi archit. vene. hacia 1760. Frontispicio, aguafuerte, $545 \times 410 \mathrm{~mm}$., Londres, Victoria and Albert Museum. 
Ciertas particularidades de las Carceri sitúan a esta obra como claro precedente de la trayectoria que el Libro de Artista tomará en los siglos posteriores. Aunque podría ser discutible considerar esta serie de grabados como un libro, no hay duda, sin embargo, de que adopta determinadas características muy propias de los Libros de Artista. Así el artista concibió la obra como un todo. Una serie de estampas que forman una única obra, y con la explícita voluntad de ponerla a la venta como una sola pieza. Por otra parte, diversos aspectos formales insisten en dicho concepto de unidad, como es el hecho de que la serie esté encabezada por un frontispicio en el que da un título general a la obra. Otro aspecto que denota dicha voluntad de unidad a la manera de un libro es que las Carceri se presentaban encuadernadas -o, mejor dicho, cosidas- todas juntas, aunque algunas estampas estaban dobladas por la mitad dado su gran tamaño. Y, finalmente, hemos de recordar que las estampas están numeradas del I al XVI lo que ratifica la perseverancia de Piranesi en mostrar su obra como una consecución de estampas bajo un orden de "lectura" que él mismo ha determinado, a modo de recorrido visual establecido por el artista, con un propósito secuencial muy próximo al de los Libros de Artista contemporáneos (Drucker, 1995).

\section{Francico de Goya - Caprichos}

La serie de los Caprichos fue la primera colección de grabados dispuestos por Goya (1746-1828) para ser vendida como conjunto (Pérez Sánchez, 1994: 55). La forma en que actualmente conocemos la serie se finalizó en 1799. Al anunciar sus estampas por primera vez en el Diario de Madrid el 6 de febrero de ese año, Goya les da el título de Colección de estampas de asuntos caprichosos, inventadas y grabadas al aguafuerte, y explica que en ellas se ha propuesto censurar los errores y vicios humanos. Con esta finalidad escoge asuntos "entre la multitud de extravagancias y embustes vulgares... aquellos que ha creído más aptos a suministrar materia para el ridículo, y exercitar al mismo tiempo la fantasía del artífice" (Camón Aznar, 198019: 35). El anuncio concluye con detalles concretos de su venta: "se vende en la calle del Desengaño, ${ }^{\circ} 1$ tienda de perfumes y licores, pagando por cada colección de á 80 estampas 325 rs. Vn.”. Con las mismas indicaciones volvió a aparecer el anuncio, bastante abreviado, en la Gazeta de Madrid el 19 de febrero del mismo año.

En un principio, Goya había clasificado las ochenta estampas en dos series de temática, a veces semejante; cada una de las cuales empezaba con un autorretrato. El orden actual no responde ni a un origen cronológico, ni a una afinidad temática de las mismas. Posiblemente, la razón por la que decidió mezclar las estampas era ocultar su significado, como precaución y defensa inteligente del ataque de la Inquisición tras retirar de la venta la peligrosa y comprometedora serie (Glendinning, 1982). Muchos son los análisis sobre la génesis y cronología de cada uno de los Caprichos, sobre el orden final en que fueron publicados o sobre la ordenación de las estampas, aparentemente inconsecuente (Sayre, 1974) (Pérez Sánchez y Sayre, 1988) (Sánchez Cantón, 1949). Una de las formas de abordar las estampas realizadas por Goya para esta colección es la que propone López Vázquez. Goya demostró su preocupación por la unidad temática de la serie, no sólo gracias al estilo personalizado de las imágenes y composiciones, a las características gráficas en el tratamiento del aguafuerte 
y el aguatinta, al tamaño de las escenas y al color de la tinta; sino también en la búsqueda de una variedad controlada de tópicos dentro de los núcleos temáticos. Éstos se pueden agrupar en: la superstición en torno al mundo de las brujas-Caprichos $44,45,47,48,60,62,64-71-$; la vida monástica y el comportamiento de los frailes -Caprichos 13, 49 en parte, 58, 74, 78-80-; y la prostitución y las maniobras celestinescas-Caprichos 15, 17, 19-22, 26, 28 y 31. Algunos sobre la educación de los niños-Caprichos 3, 4, 25-; los casamientos por interés-Caprichos 2, 14, 57-y la Inquisición-Caprichos 23, 24 (López Vázquez, 1982).

El Álbum de Sanlúcar, el Álbum de Madrid -también conocidos como Álbum A y Álbum B respectivamente (Paas-Zeidler, 1078: 18)- y la serie Sueños formaron parte del proceso de gestación de los Caprichos. En 1746, en Sanlúcar de Barrameda, Goya empezó a hacer un cuaderno de notas a tinta. La mayoría de los dibujos, o apuntes, eran de la Duquesa de Alba y de su séquito y sirvientes, en escenas íntimas y familiares que se desarrollaban en interiores o al aire libre. Del Álbum de Sanlúcar, nombre con el que se conoce este cuaderno, Goya utilizó dos de los dibujos para los Caprichos (Pérez Sánchez y Sayre, 1988). El segundo cuaderno fue empezado en Cádiz y continuado, a principios de 1797, en Madrid, por lo que le ha valido el nombre de Álbum de Madrid. De mayor tamaño que el anterior y del que se conocen noventa y cuatro dibujos numerados, también realizados a tinta. Este álbum va cambiando de carácter a medida que avanza. En la página cincuenta y cinco, Goya empezó a poner títulos a los dibujos, estableciendo relaciones entre las escenas, lo que para muchos autores ha demostrado que estos "cuadernos de apuntes" son de hecho "álbumes-diario" (Wilson-Bareau, 1992:21) en los que "Goya registraba tanto lo que pensaba como lo que veía" (Pérez Sánchez y Sayre, 1988: 113). Con la adición de comentarios escritos a sus dibujos se introducía en el ámbito de la caricatura y fue cuando empezó a germinar la idea de grabar y publicar una colección de estampas. Más tarde, empezó a realizar una serie de dibujos preparatorios para una colección de grabados, concebidos como una serie de Sueños. Con el fin de respetar su composición a la hora de grabarlos, estos dibujos preparatorios estaban realizados con una técnica especial para poder ser transferidos a la plancha de cobre. Para esta serie, Goya tomó algunas composiciones de los álbumes citados, en especial del Álbum de Madrid, y añadió algunas nuevas con la intención de publicarlas bajo el título general de Ydioma Universal. Con este fin, hizo el insigne dibujo El autor soñando sobre su mesa de trabajo (fig. 2). Este Sueño $1^{\circ}$, fechado en 1797, había de ser el frontispicio de los Caprichos, pero finalmente fue reemplazado por el autorretrato del artista. 


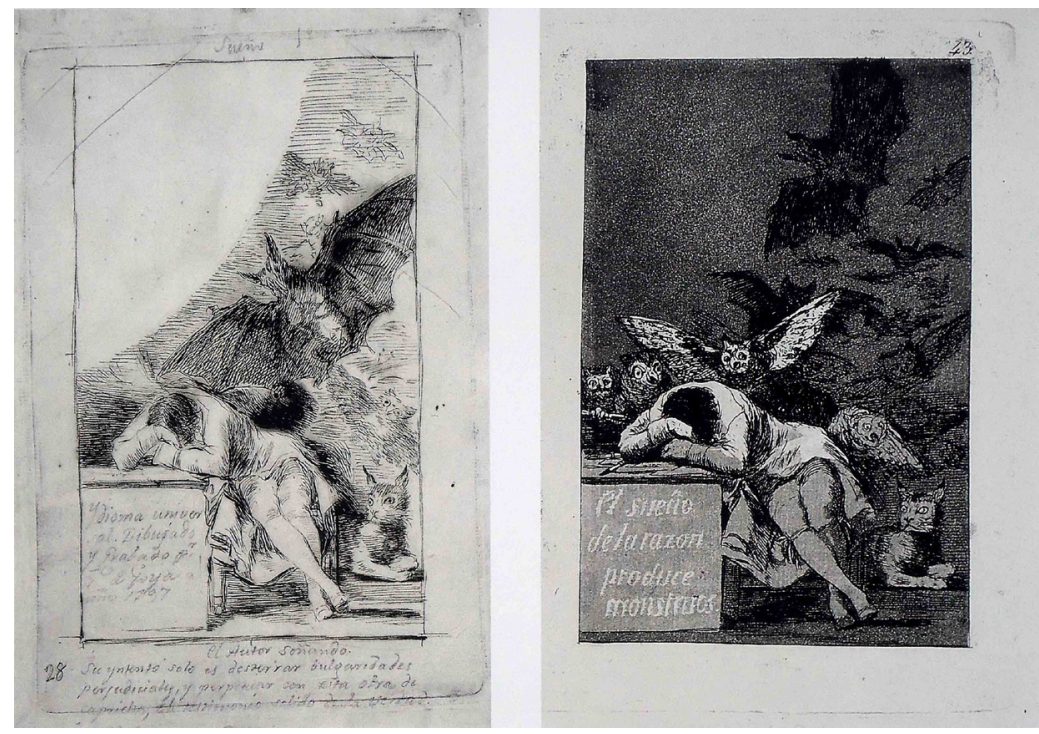

Figura 2. (Izquierda) Francisco de Goya, Sueño $1^{\circ}$ El autor soñando sobre su mesa de trabajo, 1797, dibujo sobre papel verjurado: tinta de bugallas a pluma sobre trazos de lápiz negro, 247x172 mm., Madrid, Museo del Prado. (Derecha) Francisco de Goya, Capricho 43, "El sueño de la razón produce monstruos", $1^{\text {a }}$ edición 1799, aguafuerte y aguatinta, huella de la plancha $218 \times 152 \mathrm{~mm}$. Plancha en la Calcografía Nacional, $n^{\circ}$ 214, Madrid.

En la actualidad se han conservado un número suficiente de dibujos preparatorios, que realizó para los Caprichos, que afirman que Goya trabajó previamente todas las composiciones en dibujos y posteriormente las grabó en las planchas, aunque también, algunos estudios invitan a pensar que comenzó a grabar la colección antes de haber completado los dibujos (Delteil, 1922) (Harris, 1964).

Nos hemos detenido en el análisis de la relación que existe entre el Álbum de Sanlúcar, el Álbum de Madrid y la serie Sueños con los Caprichos, porque ello aporta dos aspectos definitivos relacionados con la concepción del Libro de Artista. En primer lugar, estos álbumes a modo de cuadernos de notas, de apuntes o de viaje, no deben confundirse con un Libro de Artista. Aunque algunos de ellos, por sus admirables cualidades artísticas trasciendan los límites de un "simple" cuaderno de bocetos, ello se debe, en muchos de los casos, a otro tipo de consideraciones -como las de catalogación de la obra de los artistas. Pero, lo que sí es cierto, es que muchas veces en estos cuadernos de notas, el artista gesta frecuentemente muchos aspectos que se reflejan en sus posteriores Libros de Artista. Y, en segundo lugar, estos cuadernos a veces llegan a ser el proyecto que precede un Libro de Artista, lo cual lo convierte en un documento de muy estimable valor artístico, además de mostrar aspectos metodológicos de la creación del libro resultante.

En el mismo sentido en que justificamos la relación de las Carceri de Piranesi como primera aproximación y precedente del Libro-Arte, los Caprichos de Goya, como tal precedente, se fundamentan en iguales aspectos. Es decir, una obra conce- 
bida como un todo, como una única pieza con una unidad temática, técnica, formal y una secuencia de lectura de las estampas que la conforman.

\section{William Blake - Songs of Innocence and of Experience}

La naturaleza del genio artístico de William Blake (1757-1827) se expresa plenamente en los numerosos libros que realizó. Los Libros Iluminados-Illuminated Books- de Blake son únicos entre los que combinan texto, escrito e impreso por el poeta, con ilustraciones del mismo artista. El título que reciben estos libros procede de sus Illuminated Prints o Estampas Iluminadas. Blake denominaba así a las estampas que realizaba mediante una particular solución técnica que le permitía integrar en una misma plancha de cobre texto e imagen (Essick, 1980). Por extensión, los libros de William Blake formados por Estampas Iluminadas reciben el nombre de Libros Iluminados. Además, dicha apelación, los distingue de otro tipo de libros, de muy distinta índole, que también realizó. Blake ideó un método de impresión para la difusión de sus obras que le hacía posible publicar sus poemas y escritos a bajo presupuesto, a la vez que excluía a los intermediarios habituales en la publicación y la imprenta. Este consiste en trabajar y componer la imagen y el texto desde el momento en que se aplica el barniz sobre la plancha. Es decir, dibujando, pintando o escribiendo con el pincel y el barniz. Un "método que combina el pintor con el poeta", así lo afirmaba Blake en un prospecto informativo que publicó en 1793 para anunciar sus Libros Iluminados, esto sugiere que el artista, con toda probabilidad, utilizó el pincel para "pintar" con barniz los textos e imágenes directamente sobre el cobre. Las matrices estaban grabadas a diferentes profundidades. En algunos textos se aprecian los "defectos" de estampación producidos por mordidas irregulares, con perfiles dentados, que Blake repasaba con pluma y tinta negra. Estos diferentes niveles de la plancha ofrecen la posibilidad de estamparla en relieve y en hueco simultáneamente. Al proceder a su estampación en relieve, los contornos de este "bajorrelieve" adquieren aspectos similares a la estereotipia (Harrison, 1859). Las cualidades de textura y tono del papel se modifican, y se amplía la gama de recursos para la especulación con el color. En ocasiones, al entintar en relieve y en hueco a la vez en una única matriz, las capas de color aplicadas - a veces demasiado gruesas- se mezclaban tras la estampación, creando exquisitos efectos texturados y delicadas cualidades pictóricas. Además, más tarde, iluminaba las estampas con acuarelas, creando monotipias y monoestampas, lo que supone que cada ejemplar de cada uno de sus libros es diferente y único. Este descubrimiento fue el resultado de su gran conocimiento de las técnicas tradicionales del grabado y de una experimentación continua. Y ciertamente el editor y profundo estudioso de la obra de Blake, David Bindman (1987: 86) considera que sus libros son, a menudo, "la culminación de un largo proceso de ensayo y error, en cuyo resultado final se encuentran vestigios de ideas anteriores y se dan compromisos formales". En los libros de Blake la relación entre texto e ilustración no se reduce meramente a una cuestión de técnica. William Blake, como poeta y como pintorgrabador usaba, a la vez, uno y otro medio que se ampliaban y complementaban mutuamente. Una interrelación total entre ambos lenguajes, en la que, progresivamente, la imagen fue adueñándose cada vez más del espacio del libro. 
Songs of Innocence -Canciones de Inocencia- es, sin duda, uno de los libros más emblemáticos de William Blake. Fue impreso por primera vez en el año 1789 como obra independiente -Songs of Experience (Canciones de Experiencia) no se añadió hasta 1794. Se trata, fundamentalmente, de una compilación de cantos populares de la época e ideas personales a cerca de la inocencia como vía de libertad. Este es, junto con El Libro de Thel (1789), el primero en el que los márgenes ya no serían espacios blancos, estaban llenos de dibujos decorativos, hojas y figuras que aparecen en, entre o alrededor del texto; intimando su relación con el mensaje del texto. "En Blake, el espejo constante de referencias cruzadas entre imágenes y textos distintos es un elemento esencial" (Hamlyn, 1996: 26), y aumentando su belleza tras iluminar las estampas a mano, su obra se aproxima más a los libros iluminados manuscritos que a los libros impresos.

En aquél prospecto informativo de 1793, mencionado anteriormente, Blake publicitó la venta de Songs of Innocence y de Songs of Experience. Estaban anunciadas como obras separadas, Blake pensó que se venderían más fácilmente por separadas ya que ello abarataba el precio. Pero, todos los ejemplares conocidos de esta segunda serie están datados, según dice su portada, en 1794 y va encuadernada junto a Songs of Innocence. A partir de 1794 Blake combinó las dos series en una sola colección, Songs of Innocence and of Experience (Lincoln, 1991) (Camarés y Corruelo, 1987) (Wisckstead, 1928) (fig. 3), les dio una portada común, subtitulada "Demostración de Dos Estados Contradictorios del Alma Humana"; y transfirió, añadió, adaptó y reordenó algunas de las estampas.

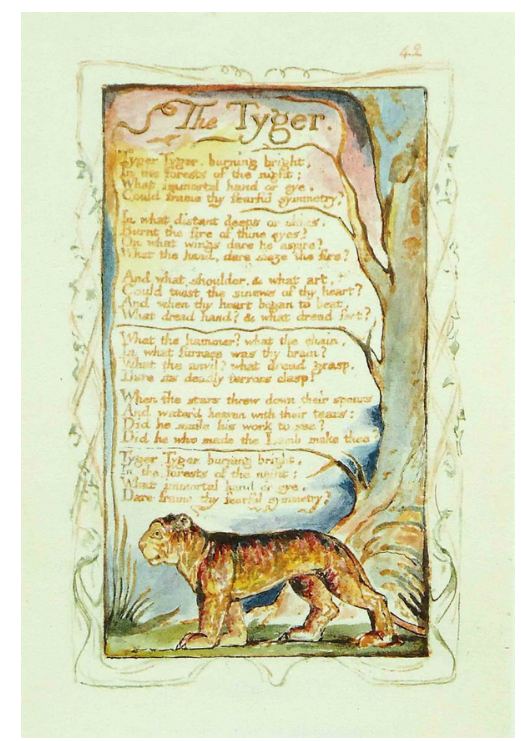

Figura 3. William Blake, Songs of Innocence and of Experience, "The Tyger" (Plancha 42), 1794, grabado calcográfico en relieve estampado en tinta de color marrón anaranjado iluminado con acuarela, oro aplicado con pincel y decoraciones pintadas a mano en los bordes, 157x141 mm. (Rogers Fund.). 
La mayoría de los poemas de Songs of Experience aparecen en un libro de notas manuscrito, heredado de su difunto hermano Robert. Muchos de estos grabados son muestras personales de la "Idea del Bien y del Mal".

Songs of Innocence y Songs of Experience se imprimieron en un mismo formato. Algunas imágenes de la segunda serie se grabaron detrás de las planchas de Innocence. Por otro lado, los títulos de una y otra serie se unen y complementan, se contrastan y se asemejan, mientras que su mayor diferencia reside en sus características visuales.

Songs of Innocence and of Experience y el conjunto de los Libros Iluminados de William Blake dan una dimensión experimental al concepto del Libro de Artista hasta entonces sin precedentes. El innovador uso que hizo del aguafuerte le permitió investigar sobre aspectos formales del libro, como por ejemplo la total integración, interrelación y simbiosis entre texto e imagen, inusual en la segunda mitad del siglo XVIII. En Blake, la labor de autor, artista y editor se fusionan en una sola persona, y ello se refleja en la unidad y autonomía de sus libros.

\section{William Morris - "The Ideal Book"}

Contra la dicotomía cada vez más acentuada entre métodos productivos, adelantos tecnológicos y calidad estética del libro, se erige en la segunda mitad del siglo XIX la imponente figura de William Morris (1834-1896) (Coote, 1990) (Faulkner, 1980).

Las novedades tecnológicas de la revolución industrial afectaron no sólo a la estética del libro, sino también a otros aspectos como la mecanización de la composición de los tipos, la fabricación del papel, la sustitución de la prensa manual por la rotativa... El libro era cada vez más el resultado de un proceso industrial y menos manufacturado; y como tal, un artefacto funcional atento a la gran demanda del mercado en detrimento de su estética. Morris reaccionó contra la degeneración de la fabricación del libro e influyó como modelo de actuación y no como modelo a imitar formalmente.

El Renacimiento, con su énfasis en los modelos clásicos y la tecnología moderna, con su destrucción de los oficios, había -según Morris- interrumpido el crecimiento natural del arte occidental, y creía que la única solución era volver a la fuente de origen: las artes u oficios medievales.

El año 1893, Morris dictaba una conferencia bajo el título "The Ideal Book" (1982: 67-73), que versaba sobre las características y elementos que "El Libro Ideal" había de poseer:

....un libro sin ornamentación puede parecer realmente bonito... arquitectónicamente ha de tener: Primero, ser fácil de leer; Segundo, un buen diseño tipográfico y Tercero, tanto si los márgenes son grandes como pequeños, ello ha de deberse a la proporción de las letras y de la página... (Morris, 1893).

Por "arquitectura" del libro Morris se refiere, principalmente, al diseño tipográfico, la encuadernación, los espacios entre las palabras y los espacios interlineales, los márgenes... y no a su decoración. Morris criticaba de los libros victorianos la debilidad de su apariencia por el tono grisáceo de la tipografía. Creía, por el contrario, 
que el rectángulo impreso debía ser tan negro como fuera posible y ello se conseguía diseñando tipografías oscuras y eliminando los espacios excesivos entre las líneas y las palabras.

Consiguió una producción de libros de una extraordinaria calidad, realzó la importancia de la calidad de las materias primas, papel de hilo, buenas tintas, una cuidada impresión y la necesidad de una encuadernación artística. Portadas de concepción neogótica en su decoración y en su interior grandes orlas florales de fondo negro donde resaltaba el blanco de las líneas, con decoraciones e ilustraciones xilográficas. Morris valoraba la autenticidad de los materiales y rechazaba las imitaciones. El material, afirmaba, es el que con sus características específicas define el proceso de fabricación, el trabajo que se le debe aplicar. Cada objeto debía ser armónico por su materia, por su forma y por el uso al que iba a estar destinado. En consecuencia, rechazaba los ornamentos faltos de sentido o los materiales demasiado preciosos o costosos en objetos de uso cotidiano.

La ornamentación debe formar una parte tan importante de la página como la propia tipografía, o se perderá en el blanco, y con la finalidad de triunfar y ser ornamental, debe someterse a ciertas limitaciones, y convertirse en arquitectura, una imagen meramente en blanco y negro, por más interesante que ésta pueda ser como imagen, puede estar lejos de ser un ornamento en un libro, mientras que por otro lado, un libro ornamentado con imágenes adecuadas para ello, y simplemente eso, puede convertirse en una obra de arte de segunda o nada, aparte de un bello edificio debidamente decorado, o una bonita obra de literatura (Morris, 1893).

Creó la Kelmscott Press y ésta se convirtió en un modelo, un paradigma para los mejores impresores de toda Europa. Una extraordinaria calidad de la impresión basada en una concepción artesanal del trabajo que se desarrolló fuera del gran centro urbano de industrialización, Londres, con una utilización de productos nobles: papel de hilo - como dijimos anteriormente-, buenas tintas, buen gusto tipográfico y una calidad estética basada en una paginación clara, un equilibrio perfecto entre los blancos y negros respecto a los márgenes, una unidad de tipos, etc.

\section{Stéphane Mallarmé - Un Coup de Dés}

El poeta simbolista francés Stéphane Mallarmé (1842-1898) (Nicolas, 1972) (Bénichou, 1995) fundamenta su obra en la persecución de la Idea por medio de símbolos. Tal Idea es la Belleza, Verdad, Infinito, Indecible. Los símbolos son, para Mallarmé, huidizos y oscuros, y no pueden captarse directamente, y por tanto, mucho menos expresarse directamente. Por ello, es por lo que la poesía no debe intentar "pintar" la cosa sino su efecto, buscando las sensaciones que reflejan. Pilar Gómez Bedate (1985: 130), en su estudio sobre el poeta, afirma que "para Mallarmé el símbolo era una especie de mapa sugerente que debía ser creado por la palabra".

La página era para Mallarmé una unidad visual que se había de dotar de un cierto material intuitivo para establecer una armonía entre nuestros diversos modos de percepción, o entre nuestros diferentes sentidos, para anticipar lo que se presentará a la 
inteligencia. Es decir, cuidaba el espacio de la página atendiendo a la distribución del blanco y el negro producida por la intensidad comparativa de la tipografía, la estructura y composición de los caracteres... Insistía en que la letra era el elemento básico del poema, y debía encontrar "movilidad" y expansión" (Mallarmé, 1956) como la inspiración en una composición musical. La disposición de los signos verbales y visuales, su evocativa interrupción del texto lineal con inesperados espacios en blanco, y un dinámico juego de tipografías señaló una revolución en la composición de la página impresa. "La busca paciente y obstinada de un lenguaje críptico que defendiese a la poesía de los lectores indignos iba a ser tarea de la vida entera de Stéphane Mallarmé" (Gómez Bedate, 1985: 9), defendiendo firmemente la poesía como un fenómeno sagrado.

Probablemente, una de las obras más enigmáticas de la literatura moderna es su último poema, Un Coup de Dés Jamais N'Abolira Le Hasard (1895). Publicado por primera vez en una versión aproximada en el periódico británico Cosmopolis en 1897, un año antes de la muerte de Mallarmé. La versión final, sin variaciones, apareció unos diecisiete años después, en 1914 (fig. 4). El autor apostó, en este poema en prosa, por una mise en page radicalmente novedosa: texto fragmentado de caracteres no uniformes que descienden la página por versos dispuestos escalonadamente. La fragmentación de sus partes se reagrupan, según dice Jean-Pierre Richard (1961: 563), entorno a un "hilo conductor latente", es decir, la frase "Un Coup de Dés Jamais N'Abolira Le Hasard", que constituye la espina dorsal del poema que gobierna el interior del conjunto. Los espacios blancos son una especie de silencio melódico, un espacio elástico que sirve para proferir la entonación: esta "distancia" blanca permite acelerar o aminorar el movimiento, tanto de lectura como de la simultánea visión de la página.

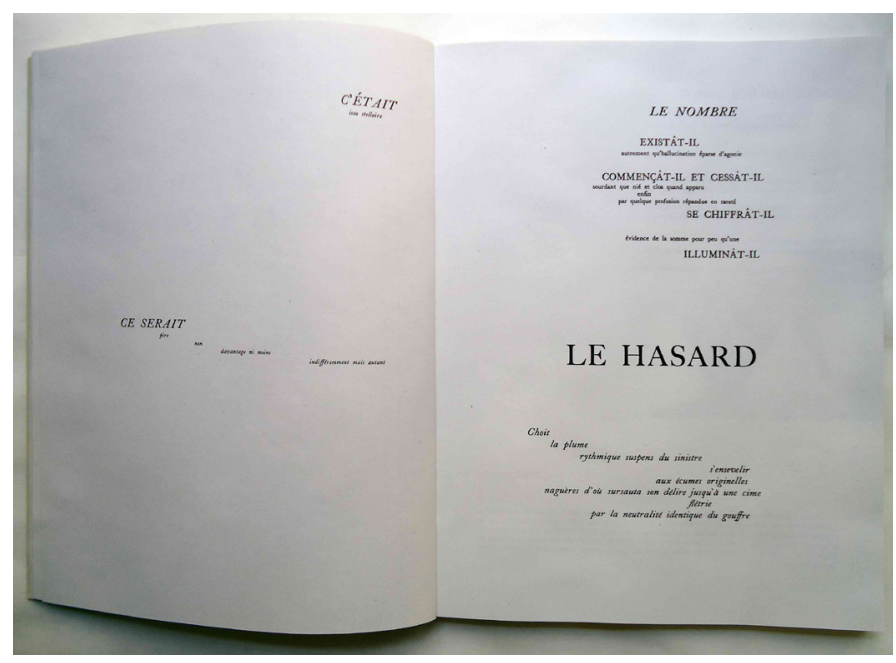

Figura 4. Stéphane Mallarmé, Un Coup de Dés Jamais N’Abolira Le Hassard, 1914 (París, Éditions Gallimard). 
El sentido del poema se articula por sí mismo en la interdependencia de su prosa y formato. Sus características físicas de tamaño y diseño son indisolubles del contenido, y usa la tipografía como auxiliar del pensamiento poético.

La obra de Mallarmé estriba en una decisión básica: "hacerse cargo de la página en blanco" y del aparente "verso-librismo" o el "poema en prosa" (Rodríguez, 1994: 12). Mallarmé manifestó que la configuración de la escritura vale como activación autosignificante de la tipografía, y sugiere, a la vez, una lectura sonora (Mallarmé, 1971). Este motivo prefigura el trabajo que las vanguardias desarrollarán hacia la "iconización" y la "sonorización" de la palabra en los Libros de Artista realizados por artistas pertenecientes a movimientos vanguardistas como el Futurismo, Dadaísmo, Surrealismo, Ultraísmo, Letrismo, Nouveau Réalisme, Zaj...

Las relaciones entre lenguaje y forma, ideas y existencia, eran problemas filosóficos para los que encontró soluciones poéticas. De su ensayo "Le Livre instrument spirituel" (Mallarmé, 1956) se desprende su propósito de buscar una síntesis entre una visión filosófica del Libro como un instrumento expansivo del espíritu y la capacidad de su forma para reflejar e incorporar pensamientos nuevos con convenciones visuales. El Libro podía ser "El Todo" y dar acceso a la divinidad a través de su forma (Mallarmé, 1956). Mallarmé siempre se refería a éste con letras mayúsculas para enfatizar la distinción entre su referencia y el objeto banal y cotidiano.

Describió minuciosamente las cualidades que "El Libro" debía cumplir, es decir, la reivindicación de la letra como elemento esencial del libro, la integración de gran variedad de tipografías, un diseño rítmico de silencios con sus dimensiones adecuadas, una constelación de signos que brindaban insospechados contrastes cromáticos (Scherer, 1957: 49-53) y, en definitiva, todos aquellos componentes que hemos destacado en su poema Un Coup de Dés.

Sin embargo, el concepto mallarmiano del Libro no finalizaba con las posibilidades que visionaba de la página, sino que insistió en el reconocimiento del "sentido del formato". Un reconocimiento que se movía en contra de la unidad "artificial" que solía estar basado en las medidas rectangulares del libro. Y, a semejanza de la disposición en partes o fragmentos del texto y las palabras, exigía la fragmentación del formato en cuadernillos o pliegos y páginas sueltas, sin numeración, hojas móviles, susceptibles de múltiples -o, tal vez, infinitas- combinaciones (Scherer, 1957: 5661). Movimientos aleatorios que reflejan el eterno y cambiante orden del universo. Una visión del destino humano al que habíamos de rendirnos frente la derrota del azar-hasard. Este cambio de unidad en las estructuras temporales responde a la llamada cuarta dimensión o dimensión espacio-tiempo, y el dinamismo que permite la movilidad de su estructura, que destemporaliza el propio tiempo, se organiza como lo hacen actualmente los más sofisticados espacios cibernéticos.

De sus textos se han realizado maravillosos Livres d'Artiste como L'Après-midi d'un faune de Édouard Manet, con el mismo artista Le Corbeau -una traducción de Mallarmé de un poema de Edgar Alan Poe-, y Poésies con ilustraciones de Henry Matisse. Pero, la relevancia de la obra de Mallarmé radica en los inmediatos y profundos efectos que tuvo, como en la sintaxis de Apollinaire, los libros cubistas de Picasso y Gris, las "palabras en libertad" del líder futurista italiano Marinetti, las subversiones tipográficas dadaístas y surrealistas, los 62 Mesostics re Merce Cunningham de 
John Cage, o el excelente homenaje que Marcel Broodthaers rinde en sus tres versiones a Un Coup de Dés.

A la vez, Un Coup de Dés anticipó e inició la reciente teoría de la "obra abierta". $\mathrm{Al}$ exteriorizar las condiciones temporales de la narrativa, y comprometer al lector en su interpretación espacial; el lector o espectador contribuye a la intervención y construcción activa de la obra de arte. Es decir, otorga al espectador el poder de modificar y acabar la obra de arte, de la misma manera que propondrá la performance. La "obra abierta" busca desestabilizar el dominio de la autoría. En 1957 Marcel Duchamp completa estos objetivos al declarar que las condiciones del "Acto Creativo" requerían que ninguna obra de arte pudiera considerarse acabada hasta que el espectador la completara, la participación del espectador como resolución de toda obra de arte (Battock, 1973: 23-26).

\section{Ambroise Vollard - Pierre Bonnard - Parallèlement}

Pocos marchands ocupan un lugar tan excelso como Ambroise Vollard (18671939) dentro del campo de la edición de libros. Junto a Daniel-Henry Kahnweiler, Albert Skira, Tériade o Iliazd, sus inmediatos colegas, Vollard regenta el puesto de honor.

François Chapon (1987: 51), en sus estudios realizados sobre la evolución del Libro Ilustrado en Francia, dedica especial atención a las aportaciones de los editores y describe, de la siguiente manera, la relación entre el pintor y el poeta en el momento en que Vollard se introdujo en el terreno editorial:

A finales del siglo XIX la unión de un pintor y un poeta con relación al libro era, a menudo, el resultado de una conjetura, si no fortuita, cuando menos, excepcional. Fruto de la amistad, de relaciones esporádicas y en la que faltaba una base económica, sin la cual era imposible la salida de una producción.

En este contexto, Vollard protagonizó un papel que paliaba esta laguna entre pintor y poeta. Tanto en cuestiones financieras, como en aspectos propios de la configuración del libro. Hans Bolliger (1987: 8) afirma con total rotundidad en la introducción del espléndido libro de referencia ineludible en esta cuestión, Picasso's Vollard Suite, que el pionero editor Vollard fue sin duda un importante marchand, pero como editor de grabados y libros, y como escritor, es como se le conocerá en la historia del arte. Es célebre por ser precursor en esa alianza, de la que surgieron brillantes ejemplares que significaron una total ruptura con los severos cánones establecidos por la tradición bibliofílica de la época (Vollard, 1946) (Drake, 1994) (Jonson, 1944).

Vollard trabajaba infatigablemente escogiendo textos -de antiguos autores clásicos franceses del siglo XIX y contemporáneos-, los tipos de las letras -los textos se imprimían en la mejor imprenta francesa, Imprimerie Nationale-, el papel más adecuado para cada libro, y poniendo a disposición de sus artistas el servicio de expertos especialistas - para las litografías el estampador Auguste Clot, y para la calcografía Louis Fort, y más tarde Roger Lacourière- que les ayudaban en las dificultades técnicas. Otorgaba a los artistas una absoluta libertad en la concepción de sus 
ilustraciones. Impuso una nueva sensibilidad basada en el equilibrio entre el nivel de independencia y sumisión de la expresión gráfica y poética.

En 1900 aparece su primer libro, Parallèlement. Esta obra, resultado de las litografías de Pierre Bonnard y los poemas de Paul Verlaine, fue rechazada por casi todos los coleccionistas y profesionales del mundo del arte, principalmente, por la novedad que suponía el uso de la litografía para las ilustraciones, ya que la técnica apropiada y reconocida para ello era la xilografía. Sin embargo, Vollard reaccionó a las críticas y al boicot con una excelente y prolífica actividad. Obteniendo, años más tarde, un exitoso y total reconocimiento.

Los poemas de Verlaine que conforman Parallèlement -cuya primera edición había aparecido once años antes- son una miscelánea de aspectos y reflexiones de la vida del poeta. Especialmente la dualidad de la naturaleza humana, y el conflicto religioso que le ocasionaba su bisexualidad. Un liberalismo hedonista combinado con una nostalgia del sueño rococó; tiznado, a la vez, por el espíritu de la escuela parnasiana -grupo al que también pertenecían, sintomáticamente, Mallarmé y Baudelaireque enfatizaba la idea del paganismo griego.

Comentamos, previamente, la escandalosa reacción que produjo el uso de la litografía para tales ediciones de bibliófilo, a lo que ahora hemos de añadir la provocación del tema, que fue tratado con explícitos desnudos entre la intimidad lésbica y la pasión heterosexual. Y por otra parte, el arrollador uso de los márgenes como espacio para la ilustración, desafiaba a la tradición a la vez que aumentaba exponencialmente las posibilidades estéticas de la página.

Pero la importancia capital de esta obra va más allá de su catalogación cronológica. Parallèlement está considerado el primer Livre d'Artiste moderno, por la autonomía y libertad de concepción de las imágenes al "interpretar" el texto, a diferencia de los Libros Ilustrados del momento cuyas imágenes le prestaban una atención literal. La armonía entre los poemas de Verlaine y las imágenes de Bonnard que se da en esta obra estableció una nueva estética y una nueva sensibilidad hacia el libro. Este "extraño" maridaje entre la impresión tradicional del texto con el revolucionario uso de la litografía para las ilustraciones, resultó en un hermoso y exquisito libro, hoy en día venerado como un pináculo del Livre d'Artiste francés (fig. 5). 


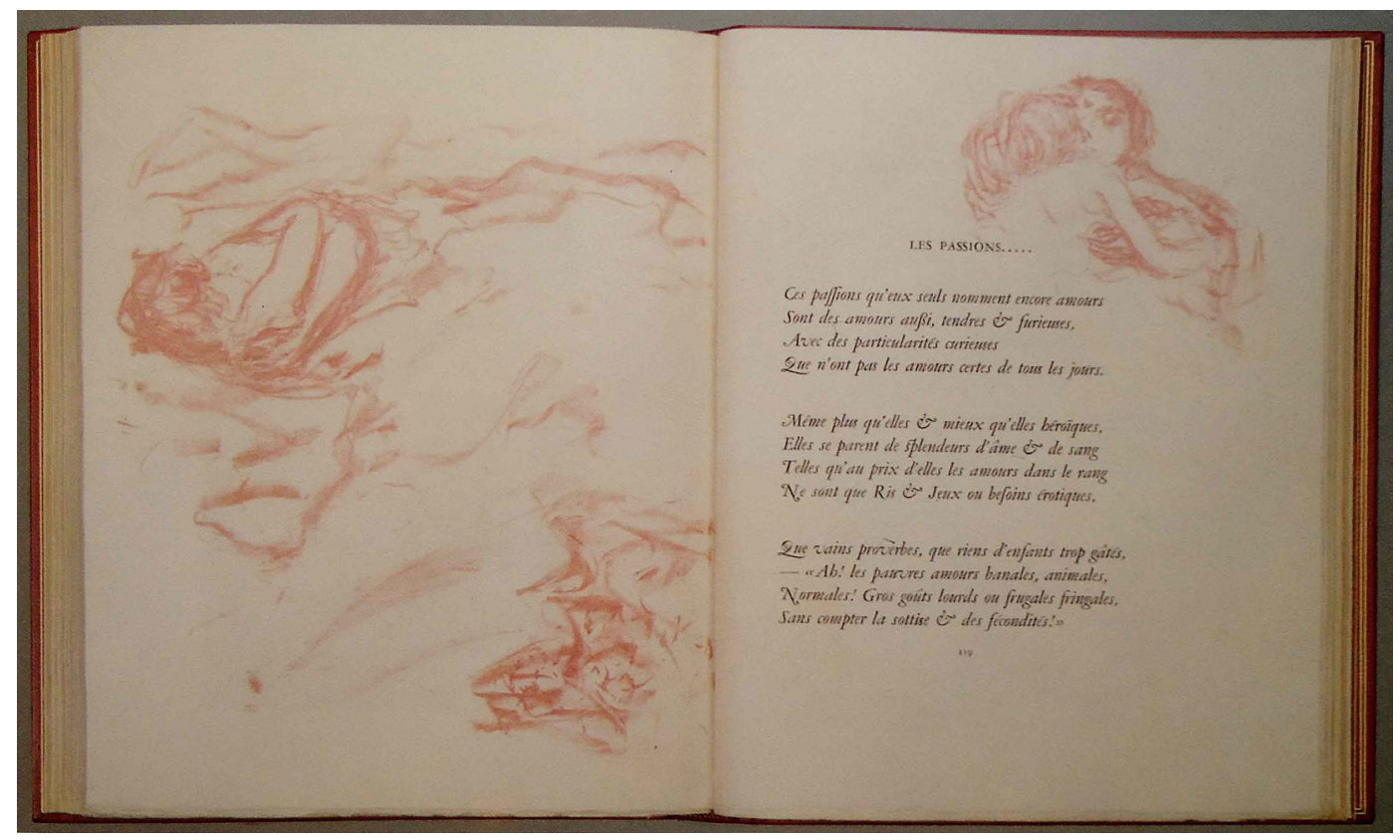

Figura 5. Pierre Bonnard, Parallèlement, 1900, litografía, 295x230 mm (Nueva York, The Museum of Modern Art, Louis E. Stern Collection).

\section{Conclusiones}

Esta selección ancestral, y muy puntual, de las primeras aproximaciones y precedentes inmediatos del Libro de Artista expone los orígenes del proceso de transformación que el Libro de Artista experimentará a lo largo de los siglos XX (Castleman, 1994) (Hartahn, 1981) (Moeglin-Delacroix, 1997) y XXI. Es decir, la decisiva importancia en el desarrollo del Libro de Artista de las obras tratadas en este artículo puede sintetizarse diciendo que adentrarse en las Carceri de Giovanni Battista Piranesi y los Caprichos de Francisco de Goya representa adentrarse en las primeras aproximaciones del concepto de serie. Ambos artistas son conscientes de estar creando un conjunto de estampas que pertenecen a un todo. No son grabados individuales, sino que se trata de una obra, así lo demuestran cuando las ponen a la venta, y consideran que el conjunto de estampas es inseparable, adquirir la obra es adquirir la totalidad de las estampas que forman la serie. Y la conciben en forma de libro encuadernado, aunque a posteriori -hoy mismo- encontremos estas estampas solitarias. De otra parte, William Blake, da al libro una nueva magnitud tanto técnica como conceptual. En tanto que poeta-grabador, en su obra Songs of Innocence and of Experience fusiona ambas disciplinas mediante un experimental y novedoso uso del aguafuerte -basado en grabar la plancha de cobre a diferentes niveles y su posterior estampación en relieve y en hueco simultáneamente-, Blake consigue integrar en una única matriz texto e ilustración, llegando a resultados gráficos que aventuran los nuevos caminos que to- 
mará el Libro Ilustrado. Mientras que el ideario de William Morris quedó reflejado en la conferencia "The Ideal Book" que dictó en 1893, además, claro está, de los volúmenes realizados en su imprenta Kelmscott Press. En su conferencia reivindicaba los aspectos artesanales del libro, como son la utilización de un buen diseño tipográfico, el respeto a ciertas normas del maquetaje de la página -equilibrio entre los espacios de los márgenes- o la selección de materiales de calidad -el papel, las tintas.... Su objetivo era crear un libro cuya "arquitectura" fuera funcional y accesible al lector, en tanto que objeto de uso. De la obra de Stéphane Mallarmé, y más concretamente de su poema Un Coup de Dés se desprenden multitud de elementos significativos que se detectarán más tarde en la mayoría de movimientos de vanguardia de todo el siglo XX. Una insólita disposición de la palabra y del texto sobre la página, fragmentada y agrupada, preservando e intercalando espacios blancos que potencian la entonación y el ritmo del poema. Reclama la plasticidad y sonoridad tipográfica, con lo que cautivará a los artistas cubistas, futuristas, dadaístas, surrealistas... y por otra parte, la trascendencia conceptual de su obra amplía la participación del lector, con un marco de actuación sobre ella propio de la performance y del arte de acción de los años sesenta y setenta. Y, finalmente, de entre las primeras aproximaciones y precedentes inmediatos del Libro de Artista debemos destacar la relevancia de Ambroise Vollard. Vollard inaugura una nueva dimensión de la figura del editor. Concibe el libro como el resultado interdisciplinar de la colaboración entre el poeta, el artista y el propio editor. Una unión cuyo resultado significará la génesis del Livre d'Artise moderno. Un renombrado ejemplo de su labor es Parallèlement con poemas de Paul Verlaine y litografías de Pierre Bonnard que supuso un cambio de dirección del Libro Ilustrado al Livre d'Artiste, gracias al protagonismo e independencia que las imágenes adquirirán, abandonando antiguos vínculos con el texto y creando de nuevos. Así pues y con estos referentes a las puertas del siglo XX, todo estaba acondicionado para la explosión creativa que el Libro de Artista iba a experimentar en el siglo que se inauguraba y que proseguiría en el presente siglo XXI.

\section{Referencias}

Battock, G. (Ed.). (1973). The New Art. Nueva York: Battock, G. ed.

Bénichou, P. (1985). Selon Mallarmé. París: Gallimard.

Bindman, D. (1987). The Complet Graphic Works of William Blake. Londres: The William Blake Trust / Tate Gallery.

Bolliger, H. (1987). Picasso's Vollard Suite. Londres: Thames and hudson Ltd.

Camarés, J. L. \& Corruedo, S. G. (1987). William Blake. Canciones de Inocencia y de Experiencia. Madrid: Cátedra.

Camón Aznar, J. (1980-1982). Francisco de Goya, tomo III. Zaragoza: Instituto Camón Aznar Caja de Ahorros de Zaragoza, Aragón y Rioja.

Castleman, R. (1994). A Century of Artists Books. Nueva York: The Museum of Modern Art.

Chapon, F. (1987). Le peintre et le livre:L'Age d'or du livre illustré en France, 18701970. París: Flammarion. 
Coote, S. (1990). William Morris: his Life and Work. Londres: Garamond.

Delteil, L. (1922). Le peintre graveur illustre XIXè et XXe siècles. vol 14 y 15. París: Da Capo Press (Reed. Nueva York, 1969).

Drake, Ch. (1994). Ambroise Vollard. Éditeur. Stuttgart: Agnew's.

Drucker, J. (1995). The Century of Artists'Books. Nueva York: Granary Books.

Essick, R. N. (1980). William Blake Printmaker. Princeton: Princeton University Press.

Faulkner, P. (1980). Against the Age: an Introduction to William Morris. Unwin: George Allen.

Focillon, H. (1918). Giovanni Battista Piranesi, 1720-1778. París: H. Laurens. También recuperado de http://archive.org/details/giovannibattist00foci

Glendinning, N. (1982). Goya y sus críticos. Madrid: Taurus.

Gómez Bedate, P. (1985). Mallarmé. Madrid: Júcar.

Hamlyn, R. (1996). William Blake (1757-1827). En VV AA., William Blake. Visions de Mons Eterns (1757-1827). Barcelona: Centre Cultural de la Fundació la Caixa.

Harris, T. (1964). Goya. Engravings and Lithography. Oxford: Bruno Cassier.

Harrison, J. (Ed.). (1859). Printing Patents: abridgments of patent specifications relating to printing 1617-1857. Londres: Printing Historical Society. Reimpreso Eyre, G. E. \& Spottiswoode, W. Patents for inventions: abridgments of specifications relating to printing. Londres.

Hartahn, J. (1981). The History of Illustrated Book. The Western Tradition. Londres: Thames and Hudson.

Johnson, U. E. (1944 ). Ambroise Vollard éditeur, 1867-1939. An appreciation and Catalogue. Nueva York: Wittenborn and Company.

Lafuente Ferrari, E. (1936). Giovanni Battista Piranesi en la Biblioteca Nacional. Madrid: Patronato de la Biblioteca Nacional.

Lafuente Ferrari, E. (1978). Los Caprichos de Goya. Barcelona: Gustavo Gili.

Lincoln, A. (1991). William Blake 'Songs of Innocence and of Experience', vol. 2. Londres: The William Blake Trust / Tate Gallery.

López Vázquez, J. M. B. (1982). Los Caprichos de Goya y su significado. Santiago de Compostela: Universidad de Santiago de Compostela.

Mallarmé, S. (1956). Le Livre instrument spirituel. En Oeuvres complètes. París: Gallimard. Recuperado de http://fr.wikisource.org/wiki/Variations_sur_un_sujet/ Le_Livre,_Instrument_spirituel

Mallarmé, S. (1971). Prefacio de Un Coup de Dés Jamais N'Abolira Le Hasard. Papua. Recuperado de http://fr.wikisource.org/wiki/Un_coup_de_d\%C3\%A9s jamais_n\%E2\%80\%99abolira_le_hasard

Moeglin-Delacroix, A. (1997). Esthétique du livre d'artiste. París: Ed. Jean-Michel Place / Bibliothèque Nationale de France.

Morris, W. (1982). The Ideal Book. En The Ideal Book. Berkeley \& Los Angeles: California University of California Press. doi: http://dx.doi.org/10.1093/libraj/ TBS-1.Part 1-2.179

(1893). The William Morris Internet Archive: Works. [Versión de Transactions of the Bibliographical Society]. Recuperado de http://www.marxists.org/archive/ morris/works/1893/ideal.htm 
Nicolas, H. (1972). Mallarmé et le Symbolisme. París: Gallimard.

Paas-Zeidler, S. (1978). Goya. Caprichos. Desastres. Tauromaquia. Disparates. Barcelona: Editorial Gustavo Gili S. A.

Pérez Sánchez, A. E. \& Sayre, E. A. (1988). Goya y el Espíritu de la Ilustración. Madrid: Museo del Prado.

Pérez Sánchez, A. E. (1994). Caprichos. En Pérez Sánchez, A. E. \& Gallego, J., Goya grabador. Madrid: Fundación Juan March de Madrid.

Phillpot, C. (1998). Artists / Author. Contemporary Artists'Books. Nueva York: American Federation of Arts.

Richard, J-P. (1961). L’Univers Imaginaire de Mallarmé. París: Seouil.

Robinson, A. (1986). Piranesi. Early architectural fantasies. A catalogue raisonée of his etchings. Chicago: University of Chicago.

Rodríguez, J. C. (1994). La poesía, la música y el silencio. (De Mallarmé a Wittgenstein). Sevilla: Editorial Renacimiento.

Sánchez Cantón, F. J. (1949). Los Caprichos de Goya y sus Dibujos preparatorios. Barcelona: Instituto Amatller de Arte Hispánico.

Sayre, E. A. (1974). The Changing Image: Prints by Francisco Goya. Boston: Museum of Fine Arts.

Scherer, J. (1957). Symbolisme du noir et du blanc y Structure et Mouvement dans le Livre. En Scherer, J., Le 'Livre' de Mallarmé. París: Gallimard.

Vollard, A. (1946). Memorias de un vendedor de cuadros. Barcelona: Ediciones Destino S. L.

Wilson-Bareau, J. (1992). Los Caprichos. Proceso Creativo y Técnico. En Goya. La década de los Caprichos. Dibujos y aguafuertes. Madrid: Real Academia de Bellas Artes de San Fernando.

Wilton-Ely, J. (1988). The Fever of the Imagination. En Wilton-Ely, J., The Mind and Art of Giovanni Battista Piranesi. Londres:Thames \& Hudson.

Wiscksteed, J. H. (1928). Blake's Innocence and Experience. Londres \& Toronto: J. M. Dent \& Sons LTD. 